\title{
NOTA
}

\section{Lenguas naturales frente a lenguajes artificiales}

\author{
Ramón Trujillo CarreÑo \\ Universidad de La Laguna \\ rtc031@gmail.com \\ Luisa Portilla Durand \\ Universidad Nacional Mayor de San Marcos \\ luisappd@gmail.com

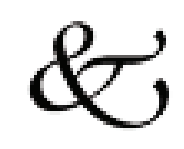 \\ I
}

Hace ya tiempo que hemos entrado en aquello que Antonio Machado (1936: 97) llamaba "ola de ñoñez y de americanismo»': la trivialización generalizada del saber y de la cultura. Y no es que esa trivialización haya significado nunca ignorancia, sino fundamentalmente la sustitución del humanismo por los métodos de las ciencias físico-matemáticas, entre las cuales se halla la Informática. Hoy «todo se hace científico» en el sentido de sustituir los productos de las culturas tradicionales por complejos «modelos formales», en ese afán por reducirlo todo a fórmulas o a razonamientos matemáticos -o imaginariamente matemáticos- El humanismo, dentro del que se había situado y desarrollado al menos una parte de la Linguística, se desacredita ${ }^{2}$ y se ve como palabrería inútil, frente a la «nueva cientificidad» de quienes ignoran el pensamiento clásico y sus productos fundamentales, como la filosofía o el arte. Para ellos no hay objetos únicos e irrepetibles, pese a que toda la buena poesía, toda la buena literatura, están formadas en cada caso por objetos únicos que se resisten a

1 «Todo deporte, en cambio, es trabajo estéril, cuando no juego estúpido. Y esto se verá claramente cuando una ola de ñoñez y de americanismo invada nuestra vieja Europa».

2 Probablemente por no haber logrado superar su nivel meramente pedagógico. 
responder a abstracciones, fórmulas, explicaciones o simplificaciones de cualquier tipo ${ }^{3}$.

Pero la dificultad principal no está en el "significado literario», que siempre se relaciona o puede relacionarse con realidades externas al lenguaje mismo, como sucede con el Hamlet, con el Quijote o con el Pedro Páramo. El problema se presenta más claramente en el significado de aquellos otros objetos «no linguísticos» en los que se percibe una identidad que podríamos llamar «no narrativa», como pueden ser la Venus de Milo, Las Meninas o el Bolero de Ravel. Porque si bien a las obras literarias podemos asignarles - aunque impropiamente - una cierta realidad externa al lenguaje mismo, no podemos, en cambio, señalarles referentes precisos a la música, a la pintura o a la escultura y arquitectura. ¿Por qué la Venus de Milo posee esa fuerte capacidad de significar si no podemos explicar de manera verosímil, o al menos precisa, qué es lo que significa? ¿O es que simplemente no significa nada y que se basta con «estar ahí»? Y lo mismo podríamos decir que sucede con las Meninas o con las sonatas para violonchelo solo de Bach. Se trata en estos casos de objetos que no parecen significar nada que esté fuera de ellos, al contrario de lo que sucede o suele suceder con los textos verbales. Lo más que puede decirse de estas cosas es que son bellas o, mejor aún, que nos parecen bellas. Lo más exacto sería afirmar que todos estos objetos "son cosas», pero entonces las confundiríamos con otras cosas que se limitan a estar ahí, pero que no nos dicen nada. ¿Pero es que la Venus de Milo, las Meninas o las sonatas de Bach nos dicen algo que se pueda decir o explicar con palabras? Frente a las palabras, "que sí pueden decirnos algo", estos otros objetos no nos dicen nada precisable. Lo único que sucede es que los entendemos o podemos entenderlos, si bien no como objetos bien definidos o pertenecientes a ese mundo externo a nosotros mismos.

El hecho es, sin embargo, que nadie podrá construir una nueva Venus de Milo, unas nuevas Meninas o un nuevo Hamlet, por poner algún ejemplo. Las disciplinas no humanísticas no podrán explicar nunca el secreto y las reglas que rigen la creación de este tipo de «objetos» poderosamente significativos. Las ciencias físico-matemáticas no podrán explicar nunca las reglas que rigen la creación de este tipo de objetos humanos que sólo capta la inteligencia. La creación, en sentido estricto, no admite reglas previas de ninguna clase ${ }^{4}$. Nadie podrá encontrar la fórmula — si es que hubo alguna- mediante la que se construyó La Fiesta, de J. R. Jiménez, la Noche Oscura, de Juan de la Cruz, el

3 Por eso, una gran parte de lo que se nos da como «arte» no pasa de ser más que pura copia o imitación.

4 Se entiende, claro está, a esas reglas a las que sólo puede llegar esa pura intuición particular de la que depende cada una. No se habla aquí de las reglas escolares comunes a los más diversos géneros literarios. 
Quijote, de Cervantes, etc. Cuando uno examina estos formidables logros verbales, comprueba que todos ellos siguen reglas o principios que nada tienen que ver con la idea de creación en que creen los lingüistas a lo Port-Royal: nadie podrá hallar jamás los secretos últimos de la sintaxis de la Noche Oscura, ni nadie repetir nunca los principios secretos que han regido la elaboración de construcciones semejantes. Y, además, no se sabe de ningún verdadero matemático que se haya empeñado en buscar las reglas que se ocultan en la construcción de las obras de arte, porque esas reglas — si podemos llamarlas así- no dependen de ningún sistema preexistente: cada verdadera obra de arte sigue reglas propias, exclusivas e irrepetibles ${ }^{5}$ y en eso consiste su grandeza y su difícil misterio. No se puede enseñar en qué consiste la belleza de un poema, de una tragedia o de una novela verdaderamente auténtica, porque las reglas que organizan ese mundo no existen como normas explícitas y universales, sino como "puros casos particulares", como construcciones técnicamente irrepetibles ${ }^{6}$. La imitación, en arte, es siempre plagio: la copia o la imitación resultan siempre falsas, porque en ellas se pierde siempre lo verdaderamente esencial del objeto. No puede decirse "qué significa» tal o cual poema, porque sus reglas - la intuitiva esencia de las reglas en que se funda- sólo existe en esa obra única y nunca en un sistema general de reglas explícitamente formulables: no existe ninguna gramática de la creación que no tenga que ver con las reglas que se ocultan en artes como la poesía, la música, la escultura, la pintura, etc. Sorprende en verdad esta vinculación entre esas artes diversas, aunque, en el fondo, todo obedece seguramente a un mismo principio intuitivo y lógicamente no formulable. Llama profundamente la atención el hecho de que las propiedades de lo estético linguiístico sean comunes a las artes no verbales como la pintura, la música o la escultura. Sin duda alguna, el secreto estético de este tipo de creaciones es semejante al que caracteriza a las obras de arte pictóricas, musicales o escultóricas. Está en ellas el mismo principio que caracteriza a los textos linguiísticos, aunque esto parezca imposible y no seamos capaces de explicarlo. Y es que el todo está en el equilibrio, ya entre palabras, ya entre sonidos, ya entre figuras, etc. Y es muy posible que se trate, en el fondo, de la misma cosa y de que lo estético esté más allá de lo que comúnmente se considera como pura gramática sin más. Que no se diga, pues, que se habla

5 Se dirá -y con razón- que el arte sigue necesariamente reglas. Pero lo que se quiere decir aquí es que, además, hay las que podríamos llamar «reglas de la intuición» que sólo capta la parte más escondida de nuestro cerebro. Las conocía Juan de Yepes y Álvarez, Juan Ramón Jiménez, Juan Rulfo, etc., y nunca podrán formularse como si fueran recetas "para uso de cualquiera». Sólo la inteligencia, en su estado más puro, puede dar cuenta de ellas, pese a que no sean explícitamente formulables.

6 Abunda ciertamente la imitación, pero a la imitación se le escapa siempre la propiedad esencial y única de la verdadera obra de arte. 
de pintura o de música, porque el secreto de estas artes es el mismo que el de las grandes obras del idioma.

Por eso, lo único que puede decir quien hable de una obra de arte es lo que opina de ella y ahí no cabe más que la pura intuición, que puede ser desde soberanamente torpe hasta divinamente inteligente. Pero la verdadera obra de arte quedará siempre a un lado y nadie podrá explicar jamás su verdad íntima y última, sino a lo sumo ayudar a penetrar en su naturaleza compleja e inanalizable, con ayuda de la intuición. Es cierto que se puede analizar un fragmento linguístico, pero sólo con los criterios de algún sistema gramatical concreto; mas nunca podrá hacerse lo mismo con el poema auténtico o con la obra de arte verdadera, en los que la esencia no consiste en las normas de ningún sistema gramatical, rítmico o lógico, previamente fijado ${ }^{7}$.

La informática y las computadoras han venido a sustituir el trabajo de los antiguos gramáticos y adivinos ${ }^{8}$, con la misma imprecisión que tiene todo lo que no se conoce a fondo. Pero el problema aquí consiste en la dificultad infinita para descubrir caminos que no están en ningún mapa; es decir, sujetos a algún sistema preciso de reglas elementales, inconfundibles y evidentes. Y, todo esto, sin contar con que «jamás se adivina nada del todo», porque para estas averiguaciones, vaticinios o adivinaciones no existe ningún programa formal fiable, por lo que una expresión cualquiera puede sugerir los más diversos referentes que puedan imaginarse, sin acercarse nunca a una verdad definitiva que no existe por sí sola. Es inútil pretender saber con exactitud qué significa de manera absoluta tal o cual palabra o tal o cual texto, porque el significado no está fuera de ellos sino en ellos mismos. Ésa es la razón por la que la noción de «estructura profunda», concebida como la verdad lógica escondida en la palabra o en el texto, no pasa de ser una ingenuidad.

\section{II}

Es cierto, por otra parte, que la tradición gramatical, incluidos los recientes y conspicuos textos académicos, no ha logrado jamás otra cosa que registrar y clasificar simples usos, ignorando permanentemente los significados esenciales de los signos, que confunde irremediablemente con las prácticas más comunes del hablar, y que reduce los temas esenciales de la sintaxis a una lógica elemental y utilitaria. Y no digamos nada de la última y famosa Ortografía

7 Es cierto que existen reglas formales para la confección de las obras de arte; pero un gran soneto, por ejemplo, añadirá siempre un espíritu especial e irrepetible a la vieja fórmula retórica de esta estrofa clásica.

8 Según el DRAE (2001: 46), adivinar se definir así: "predecir lo futuro o descubrir lo oculto», «descubrir por conjeturas algo oculto o ignorado», «acertar lo que quiere decir un enigma», «acertar algo por azar», «vislumbrar, distinguir». 
(2010), capaz de confundir a la mayor parte del mundo hispanohablante. En su afán de estar en posesión de la verdad, la Academia sólo ha sabido alimentar los intereses particulares y la política linguiística del mundo de los que hablamos el español en sus necesariamente infinitas variedades, todas legítimas siempre. Y no debemos olvidar nunca el extremado daño que hace y ha hecho ese academicismo, pretendiendo «reconquistar idiomáticamente» a la América Latina, aunque no lo vaya a conseguir jamás. Porque ya no es, ni puede ser igual, el español de Castilla al de países como México, Argentina, Colombia, Perú, etc. Se trata sin duda de una misma lengua en que se han desarrollado modalidades muy bien diferenciadas que ya no permiten confundir el español de Castilla con el de Rulfo, con el de Neruda, con el de García Márquez o con el de Vallejo, y con el de tantos otros cultivadores de nuestra lengua, ya con ese sabor a otros mundos culturales nuevos.

Pero la Filología en el Nuevo Mundo no se ha logrado desarrollar como ciencia independiente, de manera que hoy se enseña la Linguiística norteamericana por todas partes y se olvida la verdadera Filología, a la que dio tan gran impulso el venezolano Andrés Bello, ya olvidado hoy debido al logicismo que ha invadido colegios y universidades. Esa nueva Linguiística, que nada quiere saber de la literariedad, es como una nueva religión en la que se cree sin reflexionar lo más mínimo: ha llegado ya la ola de ñoñez americana de que había hablado don Antonio Machado un siglo antes.

III

Se podrá decir que para la gramática que se enseña por todas partes bien vale la gramática generativa o lógica, de donde se han ido derivando los usos y abusos de creación de lenguajes artificiales, al servicio de las nuevas técnicas de investigación que se siguen en el mundo. Pero el mal no está en que se inventen procedimientos capaces de conducir a resultados técnicos o industriales, porque eso, si se hace bien, es útil y necesario y nadie va a estar nunca en contra. El problema es que esas técnicas han asumido además la explicación de las lenguas naturales como si se tratara de las construcciones y de los problemas lógico-matemáticos que hoy usamos para resolver miles de problemas no estrictamente linguísticos. La asignatura de Lengua se ha transformado, en colegios y universidades, en una mezcla de las técnicas propias de los lenguajes artificiales con las ideas y conceptos provenientes de la vieja gramática tradicional, de lo cual ha resultado un caos incomprensible y didácticamente dañino, pues sólo conduce a la confusión entre cosas diferentes. Los lenguajes artificiales son sin duda importantísimos y su enseñanza no puede olvidarse hoy, aunque recordando siempre que nada tienen que ver con las lenguas naturales con las que nos comunicamos en la vida diaria y con las que podemos en- 
trar en la creación intelectual: algo a lo que nadie puede negarle importancia. Bien está que haya cursos de Informática o de lenguajes artificiales, pero nunca a costa de eliminar el estudio de la lengua real y de los productos presentes e históricos de estas lenguas. En la enseñanza de una lengua natural, lo principal no es sólo el estudio de la creación popular en el plano de las frases hechas, locuciones y demás construcciones del uso cotidiano, sino, sobre todo, de los textos importantes o esenciales que se hayan construido con cada lengua, que es lo único que realmente justifica a la Filología, impidiendo que todo se reduzca a cosas como la fraseología u otras disciplinas análogas. Porque fraseología y procedimientos afines sólo son una parte minúscula de lo idiomático, que es como decir "del pensamiento». Sin el pensamiento, los seres humanos serían simplemente animales y carecerían de historia, de ciencia, de leyes, etc.

Pero el pensamiento natural humano, que sólo puede tener entidad linguiística ${ }^{9}$, se acumula y forma culturas de todo tipo, mundos variados. Y luego serán esas culturas, cada cultura, las que creen los diversos sistemas sociales, los variados sistemas científicos y de conocimiento, los sistemas de la normativa social, en donde entra nada menos que el Derecho, gracias a todo lo cual podemos hoy hablar de cuanto se nos ocurra, aunque siempre sin pretender estar en el terreno de la verdad, porque la Verdad, con mayúscula, no existe. Surge de cada sistema humano que se organice gracias al lenguaje, que le permitirá pensar, inventar, fabricar e, incluso, construir sistemas para avanzar en el terreno de los conocimientos y de la explotación, inteligente o no, del planeta en que, por el momento, habitamos. La llamada Verdad no es más que el resultado de la coincidencia casual entre la expresión linguiística y la cosa imaginada.

A lo largo de los siglos, el hombre se ha servido del lenguaje para organizar sus comunidades sociales, para inventar normas de comportamiento o leyes, para crear fantasías o cuentos, para construir su propia historia — su novela-, para construir herramientas y armas con que defenderse, para inventar dioses o antidioses que los ayuden a ser libres o a sobrevivir, etc. Lo que no puede olvidarse nunca es que todas las sociedades humanas han usado siempre y siguen usando lenguas naturales para comunicarse, sistemas a veces muy diferentes entre sí, pero basados constantemente en los mismos fundamentos formales. Las lenguas humanas son «naturales» en el más preciso sentido de este término, de manera que aparecen, como el cabello o las uñas, sin que nadie las construya o las fabrique, pese a que sus reglas sean peculiares y características de cada una de ellas y no de otras cualesquiera.

9 Hay otros tipos de comunicación, como las señales, los gestos y los comportamientos animales instintivos; pero esos no son lenguajes en el justo sentido de esta palabra. 
IV

Por todo ello deberíamos intentar establecer, con la mayor claridad posible, los límites entre las diversas parcelas del saber humano y, también y de camino, evitar confusiones y mezclas entre los diversos intereses culturales de esta especie nuestra, a la que irremediablemente pertenecemos, siempre diferentes en el pensar y alguna vez iguales en los derechos que la sociedad nos concede o en las obligaciones que nos impone. Porque nos hallamos ante confusiones graves que sólo pueden llevarnos a la incomprensión o a la indeterminación de nuestros campos de pensamiento. La Informática o la Matemática, por poner algún ejemplo, no tienen nada que ver con la lengua, aunque sus postulados puedan enunciarse en español, en alemán, en inglés o en la lengua que sea, lo que demuestra, además, que no siguen las reglas de ninguna lengua particular, sea general o universal. El teorema de Pitágoras puede enunciarse en cualquier lengua del mundo, justamente porque no es una construcción linguiística —un poema-, sino una construcción elaborada con un sistema de reglas ajenas a una lengua natural determinada. Este teorema se puede decir, por tanto, en todas las lenguas justamente porque no pertenece a ninguna de ellas ${ }^{10}$. Por eso, la Informática, por ejemplo, no es un lenguaje o una clase de lenguajes —en el sentido que hemos dicho- ni tiene nada que ver con esta clase de sistemas y, por tanto, no está sujeta a una estructura gramatical natural. La Informática debe de estar constituida obviamente por un sistema de reglas y saberes sin duda muy particulares, pero indudablemente ajenos a cualquiera de los sistemas de las lenguas naturales del mundo, organizadas en complejos estructurales comunes a toda la especie humana y dotados de esa capacidad particular, de esa poeticidad, que no puede explicarse con ningún sistema de reglas.

No se puede decir, sin embargo, que las lenguas naturales - que han aparecido siempre de manera natural y sin que nadie las construyera expresamente- puedan traducirse sin más a otras lenguas naturales ${ }^{11} \mathrm{o}$ a los diversos lenguajes sustitutivos, como los de la Informática. La informatización de una lengua es siempre una manipulación de la misma y carece de las posibilidades creativas naturales que poseen todas las lenguas. No hay que olvidar que las lenguas naturales son el origen y la fuente de toda la creación humana —del pensamiento-, desde los pictogramas primitivos hasta las más sofisticadas computadoras o los sistemas informáticos más perfectos. Y no hay que olvidar

10 De todas formas, nada puede traducirse exactamente de una lengua a otra, salvo textos que tienen más bien contenido lógico que propiamente idiomático.

11 Aunque no puede olvidarse esa sutil diferencia que puede caracterizar a cualquier texto de una lengua natural. Por eso, hemos hablado de textos «intraducibles», porque su valor no tiene equivalente en una lengua diferente de aquella en que se haya construido. Es eso lo que caracteriza a la naturaleza poética de la creación humana. 
que las máquinas no pueden crear más textos que los que hayan sido concebidos desde y con una lengua natural cualquiera. Y en eso se diferencian las lenguas naturales de los productos o aparatos informáticos que sólo pueden crear lo que ya está creado, o aparentar una creatividad imaginaria, usando reglas que provienen de una lengua natural cualquiera. Pero no hay que olvidar que las reglas de la creación linguiística son infinitas y que sus posibilidades son siempre imprevisibles. Puede fabricarse una máquina que construya textos como Hamlet o Fausto, por ejemplo, pero no podrá jamás hacer otros textos que se separen de lo ya hecho, de lo ya realizado concretamente en una lengua particular dada. La capacidad de una lengua natural es simplemente infinita: no lo puede hacer todo, pero puede hacer todo lo que ningún otro ingenio humano sea capaz de hacer.

Hay, como todo el mundo sabe, dos maneras o usos del lenguaje. Una es la «normal», que es puro "discurso repetido». Podemos estar horas enteras diciendo cosas insustanciales que nos sirvan para alejar la soledad o la siempre amenazadora noticia desagradable. Incluso "lo malo» resulta reconfortante, salvo que personalmente nos parezca amenazador o peligroso. La mayor parte de la gente puede pasarse el día hablando de «lo de todos los días», pero con frecuencia no puede resistir ni media hora de lectura, aunque se trate de las banalidades periodísticas, que — como bien sabemos - no hacen más que repetir el bla-bla-bla cotidiano sin añadir más que informaciones casi siempre esperables, casi siempre banales. El pintor de brocha gorda, subido a su escalera, escucha siempre su pequeña radio casi sin prestarle atención y lo mismo hace el bañista en la playa mientras toma el sol. «El aburrimiento es el fondo de la vida» decía Unamuno (1984 [1914]: 62) y no se equivocaba: el hombre se aburre repitiendo lugares comunes y rehuyendo cualquier tipo de reflexión seria que acaso pudiera llevarlo a la desesperación, al malestar o a la angustia.

Los problemas interesantes están, pues, en la creatividad. El lenguaje humano posee una capacidad creativa cuyos límites se desconocen, por lo que podemos considerar necesaria e infinita a esa capacidad. Los ingenios informáticos, en cambio, sólo son instrumentales y pueden aprovecharse para que realicen las actividades creativas para los que se les ha programado. No existen esos monstruos informáticos que vemos en películas y en televisión, porque sólo actúan como algunos de sus directores los programan para que ejecuten las acciones que se desea.

Teniendo en cuenta todo lo dicho, debemos aprender a separar las lenguas naturales de los lenguajes artificiales, no porque estos sean irrelevantes, sino simplemente porque se trata de cosas distintas que no conviene confundir 
nunca. Ninguna máquina podrá construir jamás el Pedro Páramo o el Rey Lear, pero sí podrá ayudarnos a conocer la Luna y las posibilidades de vida en ella o la utilización de los materiales que allí se encuentran o, mejor sin duda, a conocer los secretos que se esconden en todo el material genético de los seres vivos, etc. La Informática es un descubrimiento como el de la energía atómica o de la microbiología; sin embargo, nada tiene que ver con el lenguaje natural, con las llamadas lenguas naturales. Y esto sí que es algo que conviene tener siempre en cuenta para no confundir los límites de todo saber, tanto del linguí́stico, como los de los muchos mecanismos inventados por el Hombre.

Así, lo que se pretenden dejar claros aquí son los límites entre las distintas modalidades del saber, sea del saber instintivo, sea del saber construido con la razón, es decir, por la Ciencia. A esto se iba desde el principio: a las confusiones de nivel de análisis, en especial en el terreno de las disciplinas que se imparten en los colegios, en las universidades o en otras instituciones semejantes. Y, concretamente, poner sobre el tapete el asunto de los contenidos de las diversas asignaturas y, en este caso, de las asignaturas relativas al estudio del lenguaje natural. No cuesta mucho observar cómo la llamada Filología terminó separándose o dividiéndose en Gramática o Linguiística, por un lado, y en Literatura o en Crítica Literaria, por otro, y todo ello sin contar con la aparición reciente de la Informática como disciplina afín a la Linguiística. Realmente, lo que parece más grave porque, además, parece no tener remedio, es la separación progresiva entre Lengua o Linguística, de un lado, y Literatura, de otro. Para cualquier lector o para cualquier persona culta, es evidente que no se puede estudiar la Literatura sin conocer a fondo la lengua con que ésta se construye y, a la inversa, que no se puede estudiar Lingüística sin el estudio meticuloso y serio de los textos escritos en esa lengua. No se trata de la lengua del periódico o de la calle, sino del tesoro cultural de un pueblo, que es su literatura. ¿Qué clase de Linguiística se puede explicar si no se conoce la literatura de la lengua que se enseña? ¿O es que sólo basta con los chascarrillos callejeros, con los textos de una prensa ínfima o, simplemente, con lo que se oye hablar en casa o entre los amigos? Es más que evidente que no se puede explicar ningún tipo de Lingüística si no se conoce bien lo que en la lengua correspondiente se ha hecho y escrito. Y, de la misma manera, ¿cómo se puede explicar la literatura de una lengua si sólo se sabe de esa lengua lo que sabe el simple hablante de la calle o si sólo se habla de los referentes o de las cosas o acontecimientos a que aluden los textos, olvidando de camino la esencialidad de esos mismos textos? De esa manera, el profesor de Lengua hablará de la gramática de una lengua que sólo conoce someramente y el profesor de Literatura se dedicará a contar las cosas que pasan en el transcurso de un poema o de una novela; de 
eso que suele llamarse "el argumento", como si la literatura sólo tuviera por objeto contar «lo que pasa en la calle»; es decir, la película que él imagina como resultado de la lectura. Debido a ello, se le tiene tanto miedo a textos como el Ulises de Joyce, como al Pedro Páramo de Juan Rulfo o a los profundísimos poemas de César Vallejo. Si no logran ver eso que llaman «argumento», el texto, que es lenguaje y nada más que lenguaje, se les transforma en un galimatías ininteligible. Por eso, podemos decir que no es posible la asignatura de Literatura sin un conocimiento profundo de los aspectos linguí́sticos de un texto, ni es posible la asignatura de Lengua o de Linguística al hablar sin seriedad de textos que no se conocen bien.

Lo que sí debe quedar aparte y ocupar el sitio que le corresponde es todo lo relativo a la Informática, siempre que se sepa separar los diversos ámbitos que corresponden a las lenguas naturales de aquellos otros que sólo tengan que ver con los ingenios artificiales, es decir, no naturales.

\section{Referencias bibliográficas}

MACHADO, Antonio (1971) [1936] Juan de Mairena, sentencias, donaires, apuntes y recuerdos de un profesor apócrifo, edición de José María Valverde. Madrid: Castalia.

PORTILLA DURAND, Luisa P. (2010) «El quehacer del profesor universitario de lengua», en Revista Lengua y Sociedad, 10, 1, Lima; pp. 125-132.

REAL ACADEMIA ESPAÑOLA (2001) Diccionario de la lengua española. Madrid: Espasa Calpe: S. A.

REAL ACADEMIA ESPAÑOla y Asociación de Academias de la Lengua Española (2010) Ortografía. Madrid: Espasa Calpe S. A.

TRUJILLO CARREÑO, Ramón (2001) «El oficio de enseñar». Accesible en internet: http:// sites.google.com/site/publicacionesvarias/ramontrujillo-1.

DE UNAMUNO, Miguel (1984) [1914]: Niebla. Madrid: SARPE. 